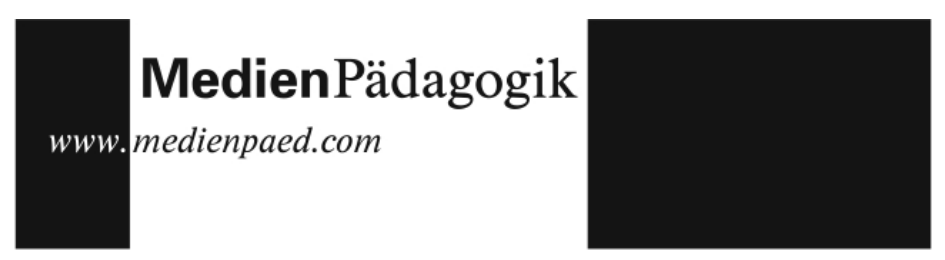

Rezensionen

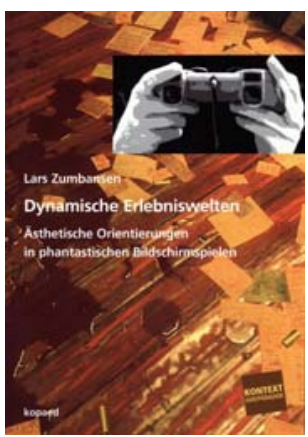

Lars Zumbansen

Dynamische Erlebniswelten

Ästhetische Orientierungen in phantastischen Bildschirmspielen

München: koaed Verlag, 2008. 247 Seiten

ISBN: 978-3-86736-116-8

$€ 18,80 ;$ CHF 29.20

\title{
Virtuelle Spielwelten
}

Medienpädagoginnen und Medienpädagogen kennen sich in den ästhetischen Lebenswelten von Kindern und Jugendlichen gut aus. Auch der gesamte Bereich der Computer- und Onlinespiele bleibt den meisten Medienpädagogen deshalb nicht verschlossen. Virtuelle Spiele sind für viele Schülerinnen und Schüler Teil ihrer ästhetischen Lebenswelt. Die Freizeit ist häufig auf Bildschirmspiele hin ausrichtet.

Die vorliegende, an der Universität Paderborn im Fach Kunstpädagogik entstandene Dissertation hat die Untersuchung von Computerspielen zum Thema, und zwar konzentriert auf die struktural-semiotische Analyse phantastischer Adventure- und Rollenspiele - und hier besonders deren narrative und ikonische Gestaltungsstrategien. Nicht enthalten sind somit pädagogische oder mediendidaktische Bezüge. Auch wird nicht der Umgang von Kindern und Jugendlichen mit dieser Spielform empirisch ermittelt. Die Arbeit wurde 2008 mit dem Nachwuchsförderpreis der Deutschen Gesellschaft für Semiotik ausgezeichnet.

Die Gründlichkeit der Studie zeigt sich an deren Aufbau. Nach kultursoziologischen Überlegungen, etwa zu Fragen der Individualität und Normierung in der «Erlebnisgesellschaft», werden Daten und Fakten zur ComputerspielIndustrie besprochen. Allgemeine spieltheoretische Erörterungen werden in Beziehung gesetzt zu Computerspielen, insbesondere zu Adventure- und Rollenspielen; ein spannendes, aber wohl auch nicht unumstrittenes Unterfangen. Als ein Hauptkapitel können die Ausführungen des Autors zu «Bildschirmspielen als narrative Weltentwürfe» gelten. Minuitiös und exemplarisch stellt Zumbansen uns seine gewonnenen Theorieaspekte hier vor. 


\section{Rezensionen}

Gleiches gilt für die «Modelle ikonischer Repräsentanz in virtuellen Spielwelten».

Aufschlussreich sind somit neben der Analyse der Narrationsstrukturen sowie deren Ursachen und Wirkungen vor allem die Studien zu den ikonischen Elementen der Bildschirmspiele. So fällt beispielsweise die eigentümliche Ästhetik von virtuellen Bildräumen auf, die oft schmutzig wirken und von Spuren der Alterung stark durchsetzt sind. Diese Charakteristik lässt sich nach Auffassung des Autors nicht einfach durch die Ästhetik des Freizeitparks (Geisterbahn) oder des Abenteuerfilms erklären (etwa nach Art der «Indiana Jones"-Filme aus den 1980er Jahren), sondern u.a. vor dem Hintergrund der digitalen Bildschirmspiele-Entwicklung. Lars Zumbansen sieht als einen Grund die steigerungslogisch optimierte und visualisierte Dokumentation subjektiver Achtsamkeit» der Produzententeams (S. 208). Die Programmierung kalkulierter Unordnung in den virtuellen Bildräumen bedeutet eben eine wesentlich größere Mehrarbeit als die serielle Reproduktion identischer Muster und Objekte, was der Computer ja leicht bietet. Eine Folge dieser komplexen, «unsauberen» ikonischen Ausgestaltung ist die erhöhte visuelle Aufmerksamkeitsbindung des Spielers. Dieses Phänomen führt aber zugleich zu einer Egalisierung und ästhetischen Normierung des gesamten neueren Spiele-Genres in dieser Hinsicht.

Lars Zumbansens äußerst detaillierte, sprachlich reflexive, hochkomplexe und zugleich anschaulich bebilderte Untersuchung sei all jenen empfohlen, die virtuelle Adventure- und Rollenspiele als Erscheinungsweise unserer Kultur semiotisch besser verstehen wollen.

Georg Peez 